\title{
Changes in the oral environment after placement of lingual and labial orthodontic appliances
}

\author{
Luca Lombardo $^{1 *}$, Yildiz Öztürk Ortan², Özge Gorgun ${ }^{3}$, Chiara Panza ${ }^{1}$, Giuseppe Scuzzo ${ }^{1}$ and Giuseppe Siciliani ${ }^{1}$
}

\begin{abstract}
Background: This study compared the oral hygiene and caries risk of patients treated with labial and lingual orthodontic appliances throughout a prospective evaluation of the status of the oral environment before and after bracket placement.

Methods: A total of 20 orthodontic patients aged 19 to 23 years were included in the study and were divided into two groups: 10 patients wore Roth labial appliance (American Orthodontics, Sheboygan, WI, USA) and 10 patients wore STb lingual appliance (Ormco Corporation, Glendora, CA, USA). Plaque index (PI), gingival bleeding index (GBI), salivary flow rate, saliva buffer capacity, salivary $\mathrm{pH}$, and Streptococcus mutans and Lactobacillus counts in saliva were determined at three time points: before orthodontic appliance placement (T0), 4 weeks after bonding (T1), and 8 weeks after bonding (T2). After appliance placement, all patients were periodically educated to the oral hygiene procedures. Wilcoxon rank and Mann-Whitney $U$ tests were used to determine intragroup and intergroup differences as regards qualitative data. To compare quantitative data between the groups, chi-square and Fisher's exact tests were undertaken, while intragroup differences were tested with McNemar test. The level of statistical significance was set at $p<0.05$.

Results: Statistical analysis of the data obtained revealed a statistically significant difference between the data of $T 0$ and $T 1$ and the data of $T 0$ and $T 2$ of the PI scores and between $T 0$ and $T 2$ of the GBI scores in the group treated with the lingual appliance. The GBI value increased significantly between $T 0$ and $T 1$ but decreased significantly between $T 1$ and $T 2(p<0.01)$ in the group treated with labial appliance. S. mutans counts increased significantly between $T 0$ and $T 2$ in the saliva samples of patients treated with lingual appliance. No statistically significant differences were found between S. mutans and Lactobacillus counts at the three terms of saliva collection in patients treated with labial appliance. No statistically significant differences were found between the two groups at the three time points as regards the salivary flow rate and saliva buffer capacity.

Conclusions: Lingual and labial orthodontic appliances showed a different potential in modifying the investigated clinical parameters: patients wearing STb lingual orthodontic appliance had more plaque retention 4 and 8 weeks after bonding, while there were more gingival inflammation and more S. mutans counts 8 weeks after bonding. No differences were found between the two groups as regards the Lactobacillus counts, the salivary flow rate, and saliva buffer capacity.
\end{abstract}

Keywords: Oral hygiene habits; Orthodontic treatment; Salivary test; Lingual appliance; Labial appliance

\footnotetext{
* Correspondence: lulombardo@tiscali.it

'Postgraduate school of Orthodontics, University of Ferrara, Via Montebello, 31 Ferrara 44121, Italy

Full list of author information is available at the end of the article
} 


\section{Background}

If a patient needs an orthodontic treatment, it should be of real benefit to him/her, by improving occlusion, dental and periodontal health, the longevity of dentition, speech, appearance, and self-esteem. Sometimes, we also have to consider patients' requirements for an esthetic or invisible treatment that is nowadays offered by aligner technology or lingual techniques. It was in 1979 when Fujita published the first article on lingual appliance, a real progress for the orthodontic practice [1]. Adults and teenagers liked better this innovative and attractive appliance above all for its esthetics [2]. It was then assumed that this appliance provoked less white spot lesions or caries development than the conventional labial appliance with obvious esthetic implication for the patient, thanks to less plaque retention due to the mechanical cleaning of the tongue on the lingual surfaces of the teeth [3]. Moreover, the fixed lingual appliance was also advisable for patients presenting some labial demineralization before starting with orthodontics. We must consider that white spots on the labial side of the teeth can occur rapidly, within the first month of therapy.

Thus, it is important to know what changes may occur in the oral environment during therapy before deciding if and how to treat a malocclusion. However, like many other interventions, orthodontic treatment has inherent risks and complications [4,5], for example, oral hygiene may be difficult to maintain during treatment, which may lead to plaque accumulation, gingival inflammation, and enamel demineralization. Caries is a common complication in orthodontics, affecting $2 \%$ to $96 \%$ of all orthodontic patients [5]. Increased caries risk during the treatment is due to several factors:

- Lesions are difficult to locate,

- Lowering of resting $\mathrm{pH}$,

- Increased volume of dental plaque,

- Rapid shift in bacterial flora [6-8].

Therefore, patient selection and the need for caries risk assessment at the beginning of the treatment play a vital role in minimizing risks of the treatment, so the clinician should be vigilant in assessing every aspect of the patient and his/her malocclusion [9-11].

Considerable time and effort has been spent on developing tests to identify individuals at risk for dental caries and periodontal damage. Different tests exist based predominantly on the quantitative estimation of Streptococcus mutans and Lactobacillus and on the determination of quantity and quality of saliva [12-14]. Positive correlations between caries activity test score and the counts of S. mutans and Lactobacillus have been reported [15].
In the literature, there are many studies investigating oral hygiene and caries risk during orthodontic treatment with labial fixed appliances [4-11,16-25], but only few are evaluating the situation with lingual techniques [1,26-34], and none has evaluated the situation with labial versus lingual appliances in the same people sample.

The aim of this study was to compare microbiological and clinical findings in patients treated with labial and lingual orthodontic appliances throughout a prospective evaluation of the status of the oral environment before and after bracket placement, by analyzing salivary and bacterial risk markers.

\section{Methods}

The present study selected 20 patients aged 19 to 23 years who responded to the following criteria:

1. No systemic disease,

2. No antibiotic or antibacterial mouthwash usage within the last 1 month,

3. Periodontal health,

4. No caries or demineralization,

5. All permanent dentition.

The 20 non-extraction class I patients were randomly divided into two experimental groups: 10 patients ( 8 females, 2 males; mean age $19.3 \pm 3.6$ ) wore Roth labial metal brackets (American Orthodontics, Sheboygan, WI, USA) and the other 10 (7 females, 3 males; mean age $22.3 \pm 3.2$ ) wore STb lingual brackets (Ormco Corporation, Glendora, CA, USA), both with a 0.018 -in $\times 0.025$-in slot system. After enamel etching, upper and lower first molar tubes and brackets were bonded in both groups with Maximum Cure (Reliance Orthodontic Products, Itasca, IL, USA). The ligature system was based on preformed 0.010-in stainless steel ligatures. After the approval of the local ethical committee and the written informed consent of the patients, clinical and microbiological evaluations were collected at three time points: before the placement of the orthodontic appliance (T0), 4 weeks after bonding (T1), and 8 weeks after bonding (T2). After the placement of the appliances, all of the patients were periodically educated to brush their teeth three times a day, according to the modified Bass technique [35], using a manual toothbrush (Oral B, Procter \& Gamble, Cincinnati, OH, USA) and fluoride toothpaste only. The study design involved two researchers: researcher A calibrated ad hoc to give oral hygiene instructions and to get clinical records and researcher B was instructed to adjust the appliances. According to the WHO guidelines for permanent dentition [36], the study registered the following:

- Decayed, missing, and filled teeth (DMFT) index. It collects the number of decayed missing, and 
filled teeth in comparison with the total examined teeth [36].

- Plaque index $(P I)$. It is recorded by circulating a periodontal probe between the bracket base and free gingival margin at six sites around each tooth; if plaque deposits are found, the site is positive [37].

- Gingival bleeding index (GBI). It records the possible bleeding produced by probing the gingival sulcus of the gingival margin with a periodontal probe; if it bleeds within $10 \mathrm{~s}$ after probing, the site is positive [37].

Plaque and gingival bleeding Index scores are expressed as percentages of the total number of tooth surfaces examined. Stimulated saliva was collected by chewing paraffin gum for $5 \mathrm{~min}$ and expectorating into a sterile cup. Stimulated saliva samples were used to determine the following:

- Salivary flow rate. It is low if $<0.7 \mathrm{ml} / \mathrm{min}$ and normal or high if $\geq 0.8 \mathrm{ml} / \mathrm{min}$.

- Salivary buffer capacity and $p H$. It was obtained by mixing $1 \mathrm{ml}$ of saliva with $3 \mathrm{ml} 0.005 \mathrm{~N} \mathrm{HCl}$ in a tube and measuring the solution $\mathrm{pH}$ after 10 min using color indicator strips (Merck KgaE, Darmstadt, Germany). It is low if $\mathrm{pH}<4.4$, borderline/limited if $\mathrm{pH} \leq 4.8$, and normal if $\mathrm{pH}=5.8$ to 7.2.

- Streptococcus mutans count. Saliva (1 ml) was placed in $3 \mathrm{ml}$ of transport fluid (VMG II) [38], serially diluted, and all plated onto mitis salivariusbacitracin agar (mitis salivarius agar (Acumedia Man Inc., Baltimore, MD, USA), Chapman Tellurite solution (Difco Lab Inc., Detroit, MI, USA), $150 \mathrm{~g}$ sucrose and $200 \mathrm{U} / \mathrm{ml}$ bacitracin (Sigma Diagnostics, St. Louis, MO, USA) [39]). After incubation at $37^{\circ} \mathrm{C}$ for $48 \mathrm{~h}$ in candle jars, the colonies were counted. It is low if $<10^{5} \mathrm{CFU} / \mathrm{ml}$, moderate if between $10^{5}$ and $10^{6} \mathrm{CFU} / \mathrm{ml}$, and high if $\geq 10^{6} \mathrm{CFU} / \mathrm{ml}$.

- Lactobacillus count. Saliva (1 ml) was placed in $3 \mathrm{ml}$ of transport fluid (VMG II) [38], serially diluted, and all plated onto Rogosa agar (Merck KGaA,

Darmstadt, Germany) [40]. After incubation at $37^{\circ} \mathrm{C}$ for $48 \mathrm{~h}$ in candle jars, the colonies were counted. It is low if $<10^{4} \mathrm{CFU} / \mathrm{ml}$, moderate if between $10^{4}$ and $10^{5} \mathrm{CFU} / \mathrm{ml}$, and high if $\geq 10^{5} \mathrm{CFU} / \mathrm{ml}$.

Descriptive statistics, including means, standard deviations, and minimum and maximum values, were calculated for all variables using the Statistical Package for Social Sciences (IBM Corporation, Armonk, NY, USA). Wilcoxon rank and Mann-Whitney $U$ tests were used to determine intragroup and intergroup differences as regards qualitative data. To compare quantitative data between the groups, chi-square and Fisher's exact tests were undertaken, while intragroup differences were tested with McNemar test. The level of statistical significance was set at $p<0.05$.

\section{Results and discussion}

Table 1 shows that, at the baseline registration of the data, no statistically significant differences were found between the two groups in the DMFT index, PI, GBI values, salivary flow rate, buffering capacity, and S. mutans and Lactobacillus counts (Mann-Whitney $U$ and Fisher's exact tests). This means that the two samples were homogeneous and comparable.

Wilcoxon rank test revealed a statistically significant increase between the data of $T 0$ and $T 1$ and the data of $T 0$ and $T 2$ of the PI scores $(p<0.05)$ and between $T 0$ and $T 2$ of the GBI scores $(p<0.05)$ in the group treated with lingual appliance. In the group treated with labial appliance, the GBI values increased significantly between $T 0$ and $T 1 \quad(p<0.05)$ and decreased significantly between $T 1$ and $T 2(p<0.01)$. No statistically significant differences were found at all time points in the two treatment groups as regards the salivary flow rate and saliva buffer capacity ( $\mathrm{pH})$. These results are reported in Table 2.

The McNemar test showed a statistically significant increase in $S$. mutans counts between T0 and T2 $(p<0.05)$ in the saliva samples of patients treated with lingual appliance, while it found no differences in the labial group. No statistically significant differences were found at the three

Table 1 Baseline registration of data

\begin{tabular}{llccc}
\hline & & $\begin{array}{c}\text { Lingual } \\
\text { technique } \\
(\boldsymbol{n}=\mathbf{1 0})\end{array}$ & $\begin{array}{c}\text { Labial } \\
\text { technique } \\
(\boldsymbol{n}=\mathbf{1 0})\end{array}$ & P value \\
\hline Oral hygiene & $\begin{array}{l}\text { DMFT index } \\
\text { (mean } \pm \text { SD) }\end{array}$ & $2.00 \pm 2.16$ & $1.90 \pm 2.18$ & NS \\
& $\begin{array}{l}\text { Plaque index } \\
\text { (mean } \pm \text { SD) }\end{array}$ & $0.47 \pm 0.18$ & $0.42 \pm 0.17$ & NS \\
& Gingival bleeding & $0.18 \pm 0.13$ & $0.31 \pm 0.21$ & NS \\
index (mean \pm SD) & & & \\
Salivary flow rate & ml/min (mean \pm SD) & $1.11 \pm 0.47$ & $1.06 \pm 0.65$ & NS \\
Buffering capacity & pH (mean \pm SD) & $5.20 \pm 0.79$ & $5.35 \pm 0.41$ & NS \\
S. mutans & Low $n(\%)$ & $0(0)$ & $0(0)$ & NS \\
& Moderate $n(\%)$ & $7(70)$ & $5(50)$ & \\
& High $n(\%)$ & $3(30)$ & $5(50)$ & \\
Lactobacillus & Low $n(\%)$ & $4(40)$ & $2(20)$ & NS \\
& Moderate $n(\%)$ & $3(30)$ & $5(50)$ & \\
& High $n(\%)$ & $3(30)$ & $3(30)$ & \\
\hline
\end{tabular}

Oral hygiene, salivary markers, and distribution of patients according to various levels of S. mutans and Lactobacillus. NS, not significant (Mann-Whitney $U$ and Fisher's exact tests). 
Table 2 Intragroup differences in plaque index, gingival bleeding index scores, and salivary markers

\begin{tabular}{|c|c|c|c|c|c|}
\hline & & $\begin{array}{l}\text { Plaque index } \\
\text { (mean } \pm \text { SD) }\end{array}$ & $\begin{array}{l}\text { Gingival bleeding } \\
\text { index (mean } \pm \text { SD) }\end{array}$ & $\begin{array}{c}\text { Saliva flow rate } \\
(\mathrm{ml} / \mathrm{min}, \text { mean } \pm \mathrm{SD})\end{array}$ & $\begin{array}{c}\text { Buffering capacity } \\
\text { (pH, mean } \pm \text { SD) }\end{array}$ \\
\hline \multirow[t]{6}{*}{ Lingual technique $(n=10)$} & TO & $0.47 \pm 0.18$ & $0.18 \pm 0.13$ & $1.11 \pm 0.47$ & $5.20 \pm 0.79$ \\
\hline & $T 1$ & $0.56 \pm 0.15$ & $0.22 \pm 0.07$ & $1.25 \pm 0.38$ & $5.30 \pm 0.85$ \\
\hline & $T 2$ & $0.59 \pm 0.16$ & $0.29 \pm 0.19$ & $1.39 \pm 0.46$ & $5.00 \pm 0.88$ \\
\hline & $T 0-T 1$ & * & NS & NS & NS \\
\hline & $T 1-T 2$ & NS & NS & NS & NS \\
\hline & $T 0-T 2$ & * & * & NS & NS \\
\hline \multirow[t]{6}{*}{ Labial technique $(n=10)$} & TO & $0.42 \pm 0.17$ & $0.31 \pm 0.21$ & $1.06 \pm 0.65$ & $5.35 \pm 0.41$ \\
\hline & $T 1$ & $0.52 \pm 0.25$ & $0.45 \pm 0.17$ & $1.32 \pm 0.45$ & $5.75 \pm 0.79$ \\
\hline & $T 2$ & $0.43 \pm 0.20$ & $0.33 \pm 0.13$ & $1.50 \pm 1.22$ & $5.50 \pm 0.41$ \\
\hline & $T 0-T 1$ & NS & * & NS & NS \\
\hline & $T 1-T 2$ & NS & $* *$ & NS & NS \\
\hline & $T 0-T 2$ & NS & NS & NS & NS \\
\hline
\end{tabular}

NS, not significant. ${ }^{*} p<0.05,{ }^{* *} p<0.01$ (Wilcoxon rank test).

time points in the two treatment groups as regards the Lactobacillus counts (Table 3).

The comparison between the two groups with MannWhitney $U$ test demonstrated no statistically significant differences at any time point as regards PI, salivary flow rate, and saliva buffer capacity (pH). Only the GBI value at $T 1$ term was significantly higher $(p<0.01)$ in the patients treated with labial appliance (Table 4).

The comparison between the two groups with Fisher's exact test demonstrated no statistically significant differences at any time point in the Lactobacillus and $S$. mutans counts (Tables 5 and 6).

\section{Discussion}

Young adults, of typical age and gender distribution of lingual orthodontic patients [41,42], were chosen as good candidates to wear lingual appliances (1) because they are more interested in esthetic appliances and then (2) because in children and adolescents, some teeth are partially erupted and not good for taking precise impressions for lingual setup and indirect bonding. Moreover, in the literature, we can find many articles analyzing various similar ranges of age $[17,22,34,43,44]$. The majority of patients enrolled in the present study were females less than 23 years of age. Stadelmann et al. found that almost a quarter of the population undergoes an orthodontic treatment, half of it with a mean age of 15 to 24 years old [45].

As regards intragroup differences, the significant increases in PI and GBI values from $T 0$ to $T 2$ in the lingual orthodontic group could be explained by the fact that plaque deposits on the lingual gingival margin of

Table 3 Intragroup differences in the distribution of patients according to various levels of S. mutans and Lactobacillus

\begin{tabular}{|c|c|c|c|c|c|c|c|}
\hline & & \multicolumn{3}{|c|}{ S. mutans } & \multicolumn{3}{|c|}{ Lactobacillus } \\
\hline & & Low $n(\%)$ & Moderate $n(\%)$ & High $n(\%)$ & Low $n(\%)$ & Moderate $n(\%)$ & High $n(\%)$ \\
\hline \multirow[t]{6}{*}{ Lingual technique $(n=10)$} & TO & $0(0)$ & $7(70)$ & $3(30)$ & $4(40)$ & $3(30)$ & $3(30)$ \\
\hline & $T 1$ & $0(0)$ & $2(20)$ & $8(80)$ & $2(20)$ & $2(20)$ & $6(60)$ \\
\hline & $T 2$ & $0(0)$ & $1(10)$ & $9(90)$ & $2(20)$ & $2(20)$ & $6(60)$ \\
\hline & $T 0-T 1$ & NS & NS & NS & NS & NS & NS \\
\hline & $T 1-T 2$ & NS & NS & NS & NS & NS & NS \\
\hline & TO-T2 & * & * & * & NS & NS & NS \\
\hline \multirow[t]{6}{*}{ Labial technique $(n=10)$} & TO & $0(0)$ & $5(50)$ & $5(50)$ & $2(20)$ & $5(50)$ & $3(30)$ \\
\hline & $T 1$ & $0(0)$ & $2(20)$ & $8(80)$ & $3(30)$ & $4(40)$ & $3(30)$ \\
\hline & $T 2$ & $0(0)$ & $2(20)$ & $8(80)$ & $1(10)$ & $5(50)$ & $4(40)$ \\
\hline & $T 0-T 1$ & NS & NS & NS & NS & NS & NS \\
\hline & $T 1-T 2$ & NS & NS & NS & NS & NS & NS \\
\hline & TO-T2 & NS & NS & NS & NS & NS & NS \\
\hline
\end{tabular}

NS, not significant. ${ }^{*} p<0.05$ (McNemar test). 
Table 4 Intergroup differences of PI and GBI scores, salivary markers

\begin{tabular}{|c|c|c|c|c|c|c|c|c|c|c|c|c|}
\hline & \multicolumn{3}{|c|}{ Plaque index } & \multicolumn{3}{|c|}{ Gingival bleeding index } & \multicolumn{3}{|c|}{ Salivary flow rate (ml/min) } & \multicolumn{3}{|c|}{ Buffering capacity $(\mathrm{pH})$} \\
\hline & $\begin{array}{c}T 0 \\
(\text { mean } \pm S D)\end{array}$ & $\begin{array}{c}T 1 \\
(\text { mean } \pm \text { SD) }\end{array}$ & $\begin{array}{c}T 2 \\
(\text { mean } \pm S D)\end{array}$ & $\begin{array}{c}T 0 \\
(\text { mean } \pm S D)\end{array}$ & $\begin{array}{c}T 1 \\
\text { (mean } \pm \mathrm{SD})\end{array}$ & $\begin{array}{c}T 2 \\
(\text { mean } \pm S D)\end{array}$ & $\begin{array}{c}T 0 \\
(\text { mean } \pm S D)\end{array}$ & $\begin{array}{c}T 1 \\
(\text { mean } \pm \text { SD) }\end{array}$ & $\begin{array}{c}T 2 \\
(\text { mean } \pm S D)\end{array}$ & $\begin{array}{c}T 0 \\
(\text { mean } \pm S D)\end{array}$ & $\begin{array}{c}T 1 \\
(\text { mean } \pm S D)\end{array}$ & $\begin{array}{c}T 2 \\
(\text { mean } \pm S D)\end{array}$ \\
\hline $\begin{array}{l}\text { Lingual } \\
\text { technique } \\
(n=10)\end{array}$ & $0.47 \pm 0.18$ & $0.56 \pm 0.15$ & $0.59 \pm 0.16$ & $0.18 \pm 0.13$ & $0.22 \pm 0.07$ & $0.29 \pm 0.19$ & $1.11 \pm 0.47$ & $1.25 \pm 0.38$ & $1.39 \pm 0.46$ & $5.20 \pm 0.79$ & $5.30 \pm 0.85$ & $5.00 \pm 0.88$ \\
\hline $\begin{array}{l}\text { Labial } \\
\text { technique } \\
(n=10)\end{array}$ & $0.42 \pm 0.17$ & $0.52 \pm 0.25$ & $0.43 \pm 0.20$ & $0.31 \pm 0.21$ & $0.45 \pm 0.17$ & $0.33 \pm 0.13$ & $1.06 \pm 0.65$ & $1.32 \pm 0.45$ & $1.50 \pm 1.22$ & $5.35 \pm 0.41$ & $5.75 \pm 0.79$ & $5.50 \pm 0.41$ \\
\hline$p$ value & NS & NS & NS & NS & $* *$ & NS & NS & NS & NS & NS & NS & NS \\
\hline
\end{tabular}

NS, not significant. ${ }^{* *} p<0.01$ (Mann-Whitney U test). 
Table 5 Intergroup differences in the distribution of the patients according various levels of Lactobacillus

\begin{tabular}{|c|c|c|c|c|c|c|c|c|c|}
\hline & & & & & Lactobacillus & & & & \\
\hline & & TO & & & $T 1$ & & & $T 2$ & \\
\hline & Low $n(\%)$ & Moderate $n(\%)$ & High $n(\%)$ & Low $n(\%)$ & Moderate $n(\%)$ & High $n(\%)$ & Low $n(\%)$ & Moderate $n(\%)$ & High $n(\%)$ \\
\hline $\begin{array}{l}\text { Lingual } \\
\text { technique } \\
(n=10)\end{array}$ & $4(40)$ & $3(30)$ & $3(30)$ & $2(20)$ & $2(20)$ & $6(60)$ & $2(20)$ & $2(20)$ & $6(60)$ \\
\hline $\begin{array}{l}\text { Labial } \\
\text { technique } \\
(n=10)\end{array}$ & $2(20)$ & $5(50)$ & $3(30)$ & $3(30)$ & $4(40)$ & $3(30)$ & $1(10)$ & $5(50)$ & $4(40)$ \\
\hline$p$ value & NS & NS & NS & NS & NS & NS & NS & NS & NS \\
\hline
\end{tabular}

NS, not significant (Fisher's exact test).

the teeth are more difficult to remove with standard oral hygiene procedures with respect to the labial side; if maintained for a long time, they represent a bacterial injury for the gingiva and can cause gingival inflammation [46].

Some studies in the literature confirm our results: Stamm et al. [34] found that, during lingual orthodontic treatment, there is oral hygiene impairment, even if data were collected afterwards by a questionnaire and the authors did not specify which parameter of oral hygiene they considered. Also, Artun [32] reported that visible plaque and gingivitis were present in up to $70 \%$ of the patients after starting the lingual treatment. Sinclair et al. [31] saw significantly elevated plaque accumulation in patients wearing lingual brackets.

According to many retrospective $[29,31,32]$ and prospective studies $[33,34]$ of the literature, wider lingual brackets cause a reduced interbracket distance and make oral hygiene procedures very difficult [1,26-28], with consequent risk for plaque accumulation and gingivitis. Many researchers in their studies declared that brackets and their components create a favorable condition for rapid plaque accumulation, decreasing of plaque $\mathrm{pH}$, enamel demineralization, and incipient carious lesions [6,47-49]. Øgaard et al. [10] and Yun-Wah Lau et al. [5] found that fixed orthodontic appliances make oral hygiene difficult and cause plaque retention even for the most motivated patients, and almost all of them experience some degree of gingival inflammation. Gingival recession and loss of alveolar bone, although multifactorial in origin [50], have been reported as one of the common sequelae of orthodontic procedures, especially when the teeth move in the presence of inflammation $[5,19]$.

Now, comparing the two groups of patients in our study, we can see that the lingual group demonstrates more difficulty in removing food and plaque deposits around the brackets, as confirmed by the literature $[33,34]$, even if we found that the labial group patients experienced a transient gingivitis at $T 1$ that was completely resolved at $T 2$. Therefore, oral hygiene instruction would be essential in all cases of orthodontic treatment, and the use of adjuncts such as sonic electric toothbrushes, interproximal brushes, chlorhexidine mouthwashes, fluoride mouthwashes, and regular professional cleaning should be reinforced [5]. However, patient motivation and dexterity are paramount in the success.

Saliva is an important modifying factor in the cariogenic potential of dental plaque; thus, it should be considered in the orthodontic treatment planning because the composition, $\mathrm{pH}$, and flow rate may influence bacterial adherence to enamel and orthodontic surfaces. According to Jensen and Bratthall [12], the number of $S$. mutans in saliva can be used for the evaluation of individual caries risk. An augmentation in stimulated salivary flow, buffer capacity, and salivary $\mathrm{pH}$ after

Table 6 Intergroup differences in the distribution of the patients according various levels of S. mutans

\begin{tabular}{|c|c|c|c|c|c|c|c|c|c|}
\hline & \multicolumn{9}{|c|}{ S. mutans } \\
\hline & \multicolumn{3}{|c|}{$T 0$} & \multicolumn{3}{|c|}{$T 1$} & \multicolumn{3}{|c|}{$T 2$} \\
\hline & Low $n(\%)$ & Moderate $n(\%)$ & High $n$ (\%) & Low $n(\%)$ & Moderate $n(\%)$ & High $n(\%)$ & Low $n(\%)$ & Moderate $n(\%)$ & High $n(\%)$ \\
\hline $\begin{array}{l}\text { Lingual } \\
\text { technique } \\
(n=10)\end{array}$ & $0(0)$ & $7(70)$ & $3(30)$ & $0(0)$ & $2(20)$ & $8(80)$ & $0(0)$ & $1(10)$ & $9(90)$ \\
\hline $\begin{array}{l}\text { Labial } \\
\text { Technique } \\
(n=10)\end{array}$ & $0(0)$ & $5(50)$ & $5(50)$ & $0(0)$ & $2(20)$ & $8(80)$ & $0(0)$ & $2(20)$ & $8(80)$ \\
\hline$p$ value & NS & NS & NS & NS & NS & NS & NS & NS & NS \\
\hline
\end{tabular}

NS, not significant (Fisher's exact test). 
placement of orthodontic appliances would be considered as protective factor.

In contrast, a rise in the levels of $S$. mutans and Lactobacillus counts is a negative risk factor to the oral environment [18]. The most common method used to identify caries-susceptible people is estimating the number of cariogenic bacteria such as Lactobacillus and S. mutans in saliva or plaque samples $[12,18,20,22]$.

As regards salivary parameters, in this study, salivary flow rate and buffer capacity did not differ significantly from the baseline to the two time points. However, we observed a significant increase in the number of patients with high levels of $S$. mutans colonization between $T 0$ and $T 2$ in the group with lingual device.

In a study with patients undergoing labial appliance treatment, Rosenbloom and Tinanoff [23] observed an increase of microbial oral population, particularly of $S$. mutans, known as the etiologic agent of dental caries [16,51]. On the other hand, Lara-Carrillo et al. [18] found that the placement of orthodontic appliances promoted a major stimulated salivary flow and buffer capacity in the subjects with significant differences in the salivary production before treatment and after debonding of the appliance. Nevertheless, patients showed a slight increase in the levels of S. mutans and Lactobacillus. Interestingly, Gorelick et al. [21] found no incidence of white spot formation associated with lingual-bonded retainers, which would suggest that salivary buffering capacity and flow rate have a role in protection against acid attack.

\section{Conclusions}

Lingual and labial orthodontic appliances showed a different potential in modifying the investigated clinical parameters; in accordance with many studies in the literature, we found out that patients wearing STb lingual orthodontic appliance had more plaque retention 4 and 8 weeks after bonding, more gingival inflammation, and more S. mutans counts 8 weeks after bonding. On the contrary, no differences were found between the two groups as regards the Lactobacillus counts, the salivary flow rate, and the saliva buffer capacity. Further research with larger patient samples and longer followup time are needed.

\section{Competing interests}

The authors declare that they have no competing interests.

\section{Authors' contributions}

YO, GS and OG were responsible for the clinical part of the study. LL, CP and GS were responsible of the study design and result analysis. All authors read and approved the final manuscript.

\section{Acknowledgments}

This study was supported by the Research Center of Istanbul University (project T-829/02062006).

\section{Author details}

'Postgraduate school of Orthodontics, University of Ferrara, Via Montebello, 31 Ferrara 44121 , Italy. ${ }^{2}$ Department of Orthodontics, Istanbul University, Istanbul, Turkey. ${ }^{3}$ Incirli Caddesi, Hur sokak 1/5 Bakirkoy, Istanbul, Turkey.

Received: 18 October 2012 Accepted: 19 April 2013

Published: 11 September 2013

\section{References}

1. Fujita K. New orthodontic treatment with lingual bracket and mushroom arch wire appliance. Am J Orthod. 1979; 76:657-75.

2. Sandham JA. Orthodontic treatment with lingually bonded brackets. Br J Orthod. 1984; 11:189-94.

3. van der Veen MH, Attin R, Schwestka-Polly R, Wiechmann D. Caries outcomes after orthodontic treatment with fixed appliances: do lingual brackets make a difference? Eur J Oral Sci. 2010; 118:298-303.

4. Cunha-Cruz J, Bakko DW, Huang GJ, Hujoel PP. The effects of orthodontic therapy on periodontal health: a systematic review of controlled evidence. J Am Dent Assoc. 2008; 139:413-22.

5. Yun-Wah Lau P, Wing-Kit WR. Risks and complications in orthodontic treatment. Hong Kong Dent J. 2006; 3:15-22.

6. Bollen AM, Cunha-Cruz J, Bakko DW, Huang GJ, Hujoel PP. The effects of orthodontic therapy on periodontal health: a systematic review of controlled evidence. J Am Dent Assoc. 2008; 139:413-22.

7. Chang HS, Walsh $L$, Freer TJ. Enamel demineralization during orthodontic treatment. Aetiology and prevention. Aust Dent J. 1997; 42:322-7.

8. Kvam E. Adverse effects of orthodontic treatment. In: Thilander B, Rönning $\mathrm{O}$, editors. Introduction to orthodontics. 2nd ed. Karlshamn: Gothia; 1995: p. 195-208.

9. O'Reilly $M$, Featherstone J. Demineralisation and remineralisation around orthodontic appliances - an in vivo study. Am J Orthod Dentofacial Orthop. 1987: 92:33-40.

10. Øgaard B, Rolla G, Arends J. Orthodontic appliances and enamel demineralization part 1. Lesion development. Am J Orthod Dentofacial Orthop. 1988; 94:68-73.

11. Travess H, Roberts-Harry D, Sandy J. Orthodontics. Part 6: risks in orthodontic treatment. Br Dent J. 2004; 196:71-7.

12. Jensen B, Bratthall D. A new method for the estimation of Streptococci mutans in human saliva. J Dent Res. 1989; 68:468-71.

13. Larmas M. Saliva and dental caries: diagnostic tests for normal dental practice. Int Dent J. 1992; 42:199-208.

14. Varma S, Banerjee A, Bartlett D. An in vivo investigation of associations between saliva properties, caries prevalence and potential lesion activity in an adult UK population. J Dent. 2008; 36:294-9.

15. Nishimura M, Oda T, Kariya N, Matsumura S, Shimono T. Using a caries activity test to predict caries risk in early childhood. J Am Dent Assoc. 2008; 139:63-71.

16. Brusca MI, Chara O, Sterin-Borda L, Rosa AC. Influence of different orthodontic brackets on adherence of microorganisms in vitro. Angle Orthod. 2007; 77:2

17. Al Mulla AH, Al Kharsa S, Kjellberg H, Birkhed D. Caries risk profiles in orthodontic patients at follow-up using cariogram. Angle Orthod. 2009; 79(2):323-30.

18. Lara-Carrillo E, Montiel-Bastida N-M, Sánchez-Pérez L, Alanís-Tavira J. Effect of orthodontic treatment on saliva, plaque and the levels of Streptococcus mutans and Lactobacillus. Med Oral Patol Oral Cir Bucal. 2010; 15:924-9.

19. Vanarsdall RL. Complications of orthodontic treatment. Curr Opin Dent. 1991; 1:622-33.

20. Pandis N, Papaioannou W, Kontou E, Nakou M, Makou M, Eliades T. Salivary Streptococcus mutans levels in patients with conventional and selfligating brackets. Eur J Orthod. 2010; 32:94-9.

21. Gorelick L, Geiger AM, Gwinnett AJ. Incidence of white spot formation after bonding and banding. Am J Orthod. 1982; 81:93-8.

22. Sukontapatipark W, El-Agroudi MA, Selliseth NJ, Thunold K, Selvig KA. Bacterial colonization associated with fixed orthodontic appliances. A scanning electron microscopy study. Eur J Orthod. 2001; 23:474-84.

23. Sakamaki SK, Bahn AN. Effect of orthodontic banding on localized oral Lactobacilli. J Dent Res. 1968; 47:2.

24. Attin R, Thoun C, Schlagenhauf U, Wiegand A, Hannong C, Attin T. Recolonization of Streptococci mutans on teeth with orthodontic appliances after antimicrobial therapy. Eur J Orthod. 2005; 27:489-93.

25. Rosenbloom RG, Tinanoff N. Salivary Streptococcus mutans levels in patients before, during and after orthodontic treatment. Am J Orthod Dentofacial Orthop. 1991; 100:35-7. 
26. Hohoff A, Fillion D, Stamm T, Goder G, Sauerland C, Ehmer U. Oral comfort, function and hygiene in patients with lingual brackets. J Orofac Orthop. 2003; 64:359-71.

27. Fujita K. Multilingual bracket and mushroom archwire technique. Am J Orthod. 1982; 82(2):120-40.

28. Scuzzo G, Takemoto K. Invisible orthodontics. Berlin: Quintessenz Verbags-GmbH; 2003.

29. Miyawaki S, Yasuhara M, Koh Y. Discomfort caused by bonded lingual orthodontic appliances in adult patients as examined by retrospective questionnaire. Am J Orthod Dentofacial Orthop. 1999; 114:83-8.

30. Miethke RR, Brauner K. A comparison of the periodontal health of patients during treatment with the Invisalign system and with fixed lingual appliances. J Orofac Orthop. 2007; 68:223-31.

31. Sinclair PM, Cannito MF, Goates $L$, Solomos LF, Alexander CM. Patient responses to lingual appliance. J Clin Orthod. 1986; 20(6):396-404.

32. Artun JA. A post-treatment evaluation of multibonded lingual appliances in lingual orthodontics. Eur J Orthod. 1987; 9:204-10

33. Caniklioglu C, Ozturk Y. Patient discomfort: a comparison between lingual and labial fixed appliances. Angle Orthod. 2005; 75:86-91.

34. Stamm T, Hohoff A, Ehmer U. A subjective comparison of two lingual bracket systems. Eur J Orthod. 2005; 27:420-6.

35. Bass CC. An effective method of personal oral hygiene. I La State Med Soc. 1954; 106(2):57-73.

36. World Health Organization. A guide to oral health: epidemiological investigations. Geneva: Oral Health Unit WHO; 1979.

37. Ainamo J, Bay I. Problems and proposals for recordings gingivitis and plaque. Int Dent J. 1957; 25:229-35.

38. Dahlén G, Pipattanagovit P, Rosling B, Möller Å. A comparison of two transport media for saliva and subgingival samples. Oral Microbiol Immunol. 1993; 8:375-82.

39. Gold OG, Jordan HV, Van Houte J. A selective medium for Streptococcus mutans. Arch Oral Biol. 1973; 18:1357-64.

40. Rogosa M, Mitchell JA, Wiseman RF. A selective medium for the isolation and enumeration of oral and fecal Lactobacilli. J Bacteriol. 1951; 62:132-3.

41. Fritz U, Diedrich P, Wiechmann D. Lingual technique—-patients' characteristics, motivation and acceptance. J Orofac Orthop. 2002; 63:227-33.

42. Hohoff A, Wiechmann D, Fillion D, Stamm T, Lippold C, Ehmer U. Evaluation of the parameters underlying the decision by adult patients to opt for lingual therapy: an international comparison. J Orofac Orthop. 2003; 64:135-44.

43. Paolantonio M, Festa F, di Placido G, D'Attilio M, Catamo G, Piccolomini R. Site-specific subgingival colonization by Actinobacillus actinomycetemcomitans in orthodontic patients. Am J Orthod Dentofacial Orthop. 1999; 115:423-8.

44. Demling A, Demling C, Schwestka-Polly R, Stiesch M, Heuer W. Short-term influence of lingual orthodontic therapy on microbial parameters and periodontal status - a preliminary study. Angle Orthod. 2010; 80:480-4.

45. Stadelmann P, Zemp E, Weiss C, Weiger R, Menghini G, Zitzmann NU. Dental visits, oral hygiene behaviour, and orthodontic treatment in Switzerland. Schweiz Monatsschr Zahnmed. 2012; 122(2):104-26.

46. Löe H. Human research model for the production and prevention of gingivitis. J Dent Res. 1971; 50:256-65.

47. Acharya S, Goyal A, Utreja AK, Mohanty U. Effect of three different motivational techniques on oral hygiene and gingival health of patients undergoing multibracketed orthodontics. Angle Orthod. 2011; 81:884-8.

48. Richter AES, Arruda AO, Peters MC, Sohn W. Incidence of caries lesions among patients treated with comprehensive orthodontics. Am J Orthod Dentofacial Orthop. 2011; 139:657-64.

49. Guzmán-Armstrong S, Chalmers J, Warren JJ. Ask us. White spot lesions: prevention and treatment. Am J Orthod Dentofacial Orthop. 2010; 138:690-6.

50. Delsol L, Bousquet P. Orthodontic treatment of gingival recession: indications. Orthod Fr. 2011; 82:269-78.

51. MacPherson LMD, MacFarlane TW, Geddes DAM, Stephen KW. Assessment of the cariogenic potential of Streptococcus mutans and its relationship to in vivo caries experience. Oral Microbiol Immunol. 1992; 7:142-7.

doi:10.1186/2196-1042-14-28

Cite this article as: Lombardo et al:: Changes in the oral environment after placement of lingual and labial orthodontic appliances. Progress in Orthodontics 2013 14:28.

\section{Submit your manuscript to a SpringerOpen ${ }^{\circ}$ journal and benefit from:}

- Convenient online submission

- Rigorous peer review

- Immediate publication on acceptance

- Open access: articles freely available online

- High visibility within the field

- Retaining the copyright to your article

Submit your next manuscript at $>$ springeropen.com 